\title{
Analysis of Incentive System in Human Resource Management of Modern Enterprises
}

\author{
Rong $A n^{1, a}$ \\ ${ }^{1}$ Xi'an International University, Shaanxi, Xi'an, China, 710077 \\ aemail,
}

Keywords: Human Resource Management; Incentive System; Enterprise Management

\begin{abstract}
As an important part of enterprise management, the establishment of incentive system is to promote the development of enterprises important primary motivation. As the core of the whole enterprise, the lifeblood of the whole enterprise is the core of the normal operation of the enterprise as an organic whole. It is also because of the importance of the staff. Therefore, it is necessary to consider the multi to take into account, it is necessary to do a good job management, develop strict rules to constrain the individual behavior of employees, but also to give employees the necessary incentive awards, so that employees work more passionate, more sense of belonging to the company. But at present, the implementation of enterprise incentive system there are still some problems, restricting the development of manpower, but also need to make some jump frames and change, to promote the development of human resources management.
\end{abstract}

\section{Introduction}

When the staff to complete the well-established job indicators, they will give employees a certain reward awards, in order to improve the enthusiasm and enthusiasm of the staff, so that employees with a positive sense of behavioral guidance, so that employees work more efficient and Passion, so as to achieve better goals, to promote better development of enterprises [1]. Employees because of this incentive with the guidance of the system and fully play their own initiative to create a better value. From the perspective of human resources management, is a necessary and efficient management measures. For the management of employees and the development of enterprises have a positive role in promoting.

\section{The Role of Enterprises Construction of Encouragement Incentives}

As Part of Corporate Culture, Incentives Has a Role in Shaping Corporate Culture. Incentive system is an important part of corporate culture, is an important driving force for the formation of corporate culture. Corporate culture is the performance of soft power, is the performance of cohesion. And corporate culture and staff positive ideology is the important performance of soft power, he let employees have more clear ideological leadership and behavioral guidance, so that collective together [2]. The corporate culture provides power for development. When we look at the corporate culture from a conscious perspective, we can clarify the guiding role of consciousness. The corporate culture is to create a positive working atmosphere for the staff, as well as a positive attitude, so that employees in the face of work, more able to play a subjective initiative, full of passion for work. For the development of enterprises to provide power. Improve the sense of belonging of employees. Corporate culture allows employees to more clearly aware of their own value, but also for the intuitive feel of the company's attention and concern to employees, is to give employees a sense of belonging and self-awareness of the important reasons. It is able to make employees independent sense of dependence, trust and security.

Improve the Enthusiasm of Employees, Improve the Competitiveness of Enterprises. Incentive system is an important measure to improve corporate performance. Incentive system is not only a positive ideological guidance, but also a more moderate and effective means of enterprise management. The standard of employee behavior in corporate culture is not mandatory for employee management, but by the use of subtle optimism to conduct behavior-oriented, so that 
employees can self-restraint, which can improve the staff's Work efficiency, but also improve the efficiency of management, and ultimately improve the performance of enterprises, improve the competitiveness of enterprises and expand the competitive advantage of enterprises. And, this positive and active atmosphere will attract more talents to join, expand the staff and the enthusiasm of the staff has greatly improved. So that enterprises in the ever-changing market environment to maintain a competitive advantage, sustainable development. Corporate culture is a direction of enterprise development indicators, to enable enterprises to fully understand the future direction of development and development concepts, so that enterprises in the changing market economy, to maintain a clear head and direction to achieve sustainable development.

\section{The Existing Problems in the Existing Enterprise Human Resources Management Incentive System}

Enterprises Do Not Attach Importance to the Incentive Measures, Leading to the Incentive System Defects. Some enterprises in the management, it is easy to ignore the establishment of incentive systems, especially some small and medium enterprises, in order to cost the compression, or because of the composition of the staff, in these enterprises simply did not carry out this building, or Is subjective choice to ignore this, this behavior seriously damaged the enthusiasm of the staff, so that many employees have no work passion, did not feel the concern from the enterprise. Of course, the construction of incentive system is more common, with the development of modern management, as well as the optimization of human resources, enterprises for the incentive system more and more profound, for the construction of incentive system is also more active [3]. However, due to the short development time, it is easy to ignore this policy, some enterprises in the incentive system requirements, there is no clear concept, for the incentive goals have not been clearly divided, leading to many metaphysical phenomenon. Not from the actual situation, do realistic, but slowly in the development of the supplement, leading to policy changes, many employees do not have a clear concept, which led to a lot of standard ambiguities, so that employees the trust of this incentive system is greatly reduced, over time will lose the incentive system should have the role.

Do Not Start from the Needs of Employees, so that the Incentive System Homogenization. Because some enterprises neglect the incentive system, there are many changes in the determination of the incentive target and the actual implementation of the policy, and there is no qualitative choice for the incentive method or the same kind of reward standard for all employees. This approach is not done from the characteristics of employees and the actual demand, so that many incentive policies do not meet the needs of employees, resulting in the expected results cannot achieve the desired results. Some of the enterprise incentive system in the development of the focus on material awards, for all employees, and did not do different treatment, there is no clear staff needs, with a single homogeneous system to manage all employees, this method not only Lack of flexibility, but also ignored the subjectivity of the staff. For some employees, the material reward is important, but for some other employees, the spirit of reward is more important, in general, the incentive mechanism is the object of the staff, so the system needs to be staff-oriented, from the staff The demand point of view, the specific things specific analysis, rather than the system homogenization, across the board.

Lack of Planning and Target. For a mature enterprise, in the different stages of staff development, different positions and different implementation projects have a different system and planning. Incentive system is the same, in different stages of development, and different ability to work, the need for targeted policy-making. The lack of a reasonable plan will make the whole system out of balance, for example, if it is not possible to make a reasonable plan for its material appreciation, the effect of this incentive will be more obvious, but this lack of planning measures long-term implementation, will result in pay imbalance, so that employees have some negative emotions. 


\section{The Proposal to Improve the Modern Enterprise Human Resources Incentive Management}

Establish A Reasonable and Feasible Incentive System. The core of modern enterprise management system is to establish a modern enterprise system, if a business management system is not perfect, there is no certain performance appraisal standard system, it is difficult to achieve the performance appraisal of employees [4]. In a business operation and management benefits are better, as a leader may make a high level of bonuses for employees, low level bonuses, or even no hair. Business employees should be effective incentives should be based on each employee's work performance to conduct an effective assessment, to develop a reasonable performance appraisal standard system, in accordance with the individual staff performance evaluation standards, so that employees understand their work to pay their own Got their own should get the reward, their efforts and no white to pay, and my heart to produce a balance, pay with the return is proportional. So as to mobilize the enthusiasm of the staff work and creativity, and promote the long-term development of enterprises, improve work efficiency for enterprises to create high efficiency.

Clarify the Needs of Employees, Multiple Incentives in Parallel. At present, many enterprises in the incentive management, incentive system is developed when the focus will be on material incentives, for outstanding staff bonuses or material prizes incentives. But it ignores the importance of the spirit, nor from the staff point of view of the problem, did not figure out the staff for the incentive needs, employees really want what form of reward, what type of reward, but simply take a unified In the form of this approach to a large extent ignored the subjective feelings of the staff. To the needs of employees and satisfaction as the starting point, the establishment of multiple incentive mechanism, not only to meet the material incentives, but also need to meet the spiritual needs of employees.

Establish an Effective Talent Incentive Management. Talent incentive management is to allow enterprises through material incentives and spiritual incentives to stimulate the enthusiasm of the staff, so as to achieve the desired business goals. Enterprises should establish a set of open and transparent personnel incentive management system, so that all employees in a fair environment to enjoy their talents, to maximize the enthusiasm of the staff to stimulate the work of every employee to know their own in the enterprise is useful [5]. Enterprise employees should separate personal interests and collective interests and we must love the mentality of everyone, to establish the trust between employees. Enterprises in order to retain the excellent talent, on the ground to allow employees to learn professional business knowledge, effective staff training, in order to better serve the enterprise. So that employees in the system under the guarantee have greater confidence in business services.

\section{Conclusion}

Employees are the main body of the development of a company, is the main force of the whole company building. The quality of the staff directly determines the level of performance level, which also determines the final business efficiency. In the company to establish the incentive system, the incentive management of employees, is to improve the enthusiasm of the staff and comprehensive performance of the important initiatives. There are still some problems in the current incentive management system, there are still some loopholes in the implementation of the loopholes need to be amended, the author according to the relevant literature on the current problems of the system were analyzed, and put forward the relevant response measures, but because of cognitive Limitations, the views of this aspect is still relatively simple, but also need more experts on this issue in-depth study and discussion. 


\section{References}

[1] Zhang Jianwei. On the role of incentives in the modern enterprise human resources management [J]. Today's Fortune magazine .2016 the first session of today's wealth forum [J]. Today's Fortune magazine :, 2016: 1.

[2] Jiang Feijie.Application of incentive system in enterprise human resource management [J]. "Decision and Information" magazine, Peking University School of Economics and Management. "Decision Forum - Management Science and Engineering Research Symposium" Proceedings ( (School of Economics and Management, Peking University, Beijing, China): 2016: 1.

[3] Wu Di Lan. Enterprise human resources management incentive system in the scientific application[J]. China Wuhan decision information research and development center, decision-making and information magazine, Peking University School of economics and management. "Decision-making forum - public management decision-making case And the Mirror Seminar "Collection[J]. China Wuhan Information Research and Development Center, Decision and Information Journal, Peking University School of Economics and Management: 2015: 1.

[4] Ding Yiping.Study on the Incentive Mechanism in the Human Resource Management of China's Public Institutions - Based on the Perspective of Institutional Economics [J].

[5] District Gui Heng. Improve the modern enterprise incentive mechanism to enhance the level of human resources management [J] .Taiyuan City Vocational and Technical College, 2008, 04: 30-33. 